\title{
Antecedent Relationships in Business and Information Technology (IT) Alignment
}

\author{
Sudesh Naidu \\ Marius Pretorius \\ University of Pretoria \\ Email: Sudesh.Naidu@resbank.co.za
}

Doi:10.5901/mjss.2014.v5n27p391

\begin{abstract}
The literature suggests that the solution to business and IT alignment may lie in the antecedents of alignment. This study attempts to establish the role, mode of operation and sourcing option of the IT department as antecedents to alignment and show how they are related to one another. A survey was deployed within a case organization to demonstrate the measurement, analysis and interpretation of the alignment antecedents and the plausibility of the IT department being in an anomalous state with respect to alignment. The main contribution of this research is to create awareness of the antecedent variables of alignment by defining them, showing the relationships between them, and showing how they can be measured. Finally, the research aims to propose a framework to analyse the current role-mode state and sourcing options of an IT department and to use this information to determine the viable strategic options for an IT department.
\end{abstract}

Keywords: Business-IT alignment; alignment; IT management; IT strategy; alignment antecedents; mode of operation; sourcing options; role of IT

\section{Introduction}

The alignment of IT strategies with the goals of the organization has long been a very sought-after state to achieve promising superior firm performance (Dong et al., 2008:348; Garg \& Pellissier, 2005:33; Sanders, 2005:4; Singh \& Woo, 2009:177), competitive advantage (Avison et al., 2004:223; Kearns \& Lederer, 2003:1), organizational growth (Raymond \& Bergeron, 2008:577; Wakabayashi, 2008:663) and IT credibility (Chen, 2010:9; Tarafdar \& Qrunfleh, 2010:107). At the same time it has also proved a very difficult state to achieve in practice: one that has eluded practitioners for several decades (Singh \& Woo, 2009:177; Tallon, 2007:227; 2011:9; Ullah \& Lai, 2011:21). A review of the field of business and IT alignment was carried out with the intention of determining whether the field was mature enough for practitioners to implement alignment. The conclusion was that the theory base was mature enough and that the reason for the persistence of the alignment problem must lie in the application of theory to practice, or contextualizing the problem.

There is evidence in the literature of problem-solving theory that links the context of a problem and its solution. That is, a problem is more likely to be solved if all the elements of the context of the problem are taken into consideration. As the context of the alignment problem lies in the environment within which alignment is being practised, it followed naturally to consider shifting the focus of the business-IT alignment problem to the environmental antecedents of alignment. Their study proposed that the role of the IT department within the organization was a fundamental antecedent to business and IT alignment. Chan and Reich (2007:311), after a review of the field of business and IT alignment, also came to the conclusion that the antecedents were important to the alignment problem. They recommended that future research not only identify the antecedents of alignment but also explore the interrelationships. In an attempt to fill this gap, this study therefore introduces two other antecedent variables that are closely related to the role of the IT department; namely, the mode of operation of the IT department and the sourcing option of the IT department.

The mode of operation of the IT department, within this study, is defined as the degree of responsiveness with which the IT department executes its functions. Mode of operation can vary on a continuum between two extremes; on the one end the department may be completely reactive and on the other end completely proactive. The reactive mode of operation refers to an IT department that supplies IT services only if and when they are demanded by business. Typically, the proactive mode of operation refers to an IT department that attempts to hedge the time delay between technology discovery and technology use. New technologies are often discovered through experimentation in research and development (R\&D) facilities, and it usually takes some time before the prospective use of a new technology is realised in business. In order to harness the benefits of a new technology before its competitors, an organization needs to be 
continuously researching technologies and matching them to its business processes and to prospective market opportunities. As technology research is expensive and the dependence on technology may vary across different businesses, it is clear that the mode of operation of the IT department is probably largely dependent on business strategy, and the role of the IT department mandated by the organization.

A second antecedent of the alignment of business and IT introduced in this study is the sourcing option of the IT department. Within this study the sourcing option of the IT department is defined as the location of core IT skills relative to the host organization. An IT department can either keep its core IT skills, such as infrastructure support, software development and desktop support, in-house, or they may be outsourced. Keeping core IT skills in-house results in faster response times to IT issues, but also means having to maintain a career path for IT professionals within the organization. Outsourcing core IT skills relieves the organization of maintaining a career path for IT professionals, but comes at the expense of generally slower response times and higher temporary costs when there are IT issues. It is clear therefore that the IT sourcing option is dependent on the IT strategy of the organization. In particular, it may affect the mode of operation and the role of the IT department.

The main purpose of this study is therefore to investigate the mode of operation and sourcing option of the IT department as antecedents to alignment, determine how they are related to the role of the IT department, and finally, show how they could be used to reach a point of stability that would facilitate alignment within the context of a particular organization. In particular, we want to know if there are combinations of these antecedents that set the boundary conditions for a clear alignment strategy, and whether there are conversely combinations that hamper alignment. In order to answer these primary questions, the following detailed research questions were set and investigated in the sample organization to enhance understanding of the relationships:

- Is the current perception of the mode of operation of the IT department different from what the organization would ideally want it to be?

- Do the current perceptions of the mode of operation of the IT department vary across function and department?

- Do the ideal perceptions of the mode of operation of the IT department vary across function and department?

- Should IT be outsourced or kept in-house?

- Do resource sourcing preferences vary across function and department?

Since the context of alignment is of prime importance and we wanted to better understand the relationships, this study was scoped to a particular case organization. The units of observation were therefore the employees within the organization. The demographic splits on this population were function and department. The function demographic included categories of managerial, technical and administrative functions, or combinations thereof. The department demographic had two options: IT department or client department.

The rest of the article is structured into four parts. First, the key literature on business-IT alignment is briefly reviewed, showing the shift of research focus towards antecedents. This is followed by a description of the research methods. Following the presentation of the findings, the article concludes with a discussion of the findings, including their implications and directions for future research.

\section{Literature Review}

\subsection{Business and IT alignment - an elusive problem}

The alignment of business and IT is a long-standing issue that has eluded practitioners in the field despite an extensive theory base (Brown, 2007:1157; Grant, 2003:159; Reich \& Benbasat, 2000:81; Smaczny, 2001:797; Tallon, 2007:228; Valorinta, 2011:46). The earliest attempts to align business and IT are mentioned by Valorinta (2011:55) as being about four decades ago. Others mention the problem persisting for two or three decades. Although there is not much consensus in the literature about the exact persistence of the business-IT alignment problem, it can safely be said to have existed for at least two decades. Furthermore, the literature shows that alignment is consistently a top issue for Chief Information Officers (CIOS) and technology managers (Baets, 1996:155; Broadbent et al., 1994:411; Castellanos \& Correal, 2013:61; Huang \& Hu, 2007:173; Reich \& Benbasat, 2000:81).

The reason for the persistence of business-IT alignment problem, and the consistency with which it appears on the to-do lists of IT managers, is hypothesised to be twofold. On the one hand, achieving a state of business and IT alignment is deemed to be difficult (Grant, 2003:159; Lepmets et al., 2012:1448; Norton, 2002:13; Silva et al., 2007:232; Tallon, 2007:230). For example, Norton (2002:13) explains that IT has a more difficult time aligning itself with the 
business strategy than other departments because technology is complex and difficult to understand. He adds that much IT infrastructure is difficult to link to applications and projects, and is therefore difficult to justify to business executives. Lepmets (2012:1448) mentions that software systems have become large and interconnected, making it difficult to articulate their purpose and goals. On the other hand, despite these difficulties, there is the allure of superior business performance that keeps researchers and practitioners hopeful that alignment could help their situation (Cao \& Hoffman, 2011:1127; Chen, 2010:9; Cragg et al., 2002:122; Garg \& Pellissier, 2005:33; Singh \& Woo, 2009:177). These studies all provide empirical evidence that alignment of business and IT leads to superior firm performance. It is the quest to overcome these difficulties and the allure of superior performance that are responsible for the persistence of the business-alignment problem. However, under perfect conditions, these two opposing drivers should not exist together. It therefore appears that there is a distinct disparity between what researchers find in their studies and what practitioners are experiencing in practice.

\subsection{Context: possible key to the alignment problem}

We reviewed the field of business-IT alignment with the intention of determining whether the field was mature enough for practitioners to implement. The conclusion drawn was that the field was mature enough and that the disparity must come from difficulties in applying theory to practice or, in particular, applying theory to the context of the problem.

In subsequent studies, it was reported that there is a theoretical link in problem-solving theory between the context of a problem and its solution. Kokinov and Yoveva (1996:1) explain that in typical problem solving it is taken for granted that one starts with a clear problem description and that little attention need be paid to causal entities in the environment that might influence the problem-solving process. Jonassen (2000:68) points out, however, that most problems in everyday and professional contexts are embedded in those contexts and therefore require the problem solver to construct a problem space that includes relevant information from the context. Augier et al. (2001:125) mention that studies on how firms solve complex problems suggest that context and contextualization are central elements of problem solving. They add that unstructured and complex problems are created, shaped and solved in the process of choosing, and that it is in this process that context emerges and transforms. It is therefore quite clear that the context of a problem is of significant importance to problem-solving. In the application of our business-IT alignment problem, this finding could suggest a reasonable solution to the disparity between theory and practice mentioned above. That is, the reason for the failure to apply alignment theories in practice stems from a lack of focus on context.

\subsection{Antecedents - the implementation of context}

Focusing on the context of the business-IT alignment problem effectively shifts focus onto the prerequisites for solving the alignment problem, here termed the antecedents: those variables that would help to give the practitioner a clearer view of the context within which business and IT alignment needs to be applied. The literature confirms that the role of the IT department within the organization is one of the fundamental antecedents to solving the problem of aligning business and IT. Chan and Reich (2007:311), following their review of the field of business and IT alignment, mention that researchers should focus on the antecedents. They further point out that rather than merely listing the antecedents, researchers should explore the relationships between them. Van der Zee and De Jong (1999:154) express a similar view, mentioning that a future challenge is to explicitly understand the prerequisites for business-IT alignment in terms of culture, skills and responsibilities.

\subsubsection{Mode of operation of the IT department}

The introduction of the mode of operation of the IT department as an antecedent to alignment can be justified in two ways; the first based on reported research and the second on logical reasoning.

A study by Tan (1995:171) reported relationships between the type of strategy of an organization, the organization's view of the IT department and the responsiveness of the IT department. If an organization had an aggressive business strategy, then it was more likely to view the IT department as a strategic partner. Furthermore, if the IT department was seen as a strategic partner it was more likely to be more responsive. Similar to Tan's variable, termed the view of the IT department, we define the role of the IT department antecedent variable as the mandate given by the host organization to the IT department. The role of the IT department could thus range from utility service provider to strategic business partner. The role of the IT department is therefore very similar to Tan's view of the IT department, since the mandate given by the organization is essentially how it views the role of the IT department. The mode of 
operation of the IT department antecedent as defined in this study is similar to Tan's responsiveness of the IT department, since the mode of operation has to do with how the IT department responds or reacts to business requests. This would imply a relationship between the role of the IT department and the mode of operation of the IT department. Based on Tan's theory, it could therefore be predicted that if the role of the IT department was that of a strategic business partner the mode of operation of the IT department would be proactive. Conversely, if the role of the IT department was that of a utility service provider then the mode of operation of the IT department would be reactive.

A supportive way of introducing the mode of operation of the IT department as an antecedent that is related to the role of the IT department is through logical reasoning. For instance, if the role of the IT department within the organization is that of a utility service provider then IT services are not seen as a core function of the organization. The IT department would therefore be mandated to supply basic services at low cost and on-demand only. It would then make business sense for IT to behave in a reactive manner since, in such a scenario, the IT department would not have a research and development (R\&D) division to proactively experiment with new technologies, as that would be considered wasteful of financial resources at times when there was no direct business demand for it.

Conversely, if the role of the IT department is that of a strategic business partner, it would probably be involved with business in strategy-making, it would constantly be performing R\&D on new technologies and proactively matching these technologies to the needs of the organization. Hence, if the role of the IT department is that of a strategic business partner, the mode of operation of the IT department is likely to be proactive.

In practice the mode of operation of the IT department therefore impacts directly on the service level agreements (SLAs) between IT and its client departments. It also impacts on the IT department's ability to capitalise on the opportunities presented in new, innovative technologies and their ability to apply them to the business context.

\subsubsection{Sourcing option of IT}

In keeping with Chan and Reich's (2007:311) condition of focusing on related antecedents and Van der Zee and De Jong's (1999:154) condition of considering prerequisites or antecedents in terms of culture, skills and responsibilities, this study introduces sourcing option of IT as a further antecedent to business-IT alignment. Within this study the sourcing option of IT refers to the location of IT skills relative to the host organization. That is, should core IT skills, in particular those related to infrastructure, software development and desktop support, be housed within the organization or outside it?

There is an ongoing debate between business and IT managers about whether IT services should be outsourced or kept in-house. Many believe that, since IT is often not a core function of the organization, it should be outsourced. Others believe that if the business is highly dependent on technology then IT should be kept in-house. Some believe that outsourcing is cheaper than keeping IT staff in-house in the long run. This is because, even though outsourced staff are more expensive when compared with paying the salaries of in-house staff, outsourced services are only temporary. Others believe that often outsourced staff are used continuously because business demand for IT is continuous, and therefore outsourcing is more expensive. Some believe that outsourced staff can introduce superior technical skills into the organization. Others believe that their lack of contextual knowledge of the business of the organization results in many more expensive blunders. The responsiveness of an external vendor to IT problems in a timeous manner, especially when the vendor is servicing other organizations, is also a concern. It is therefore safe to say that the sourcing issue can be very complex and dependent on the context.

The sourcing option of IT therefore appears to be related to both the above-mentioned antecedents of the role of the IT department and the mode of operation of the IT department. For instance, if the core IT skills such as infrastructure support, software development and desktop support were outsourced, then the IT department would effectively be composed of administrative staff. Such an IT department will automatically be forced into the role of a utility service provider, since it will only be capable of the administrative tasks such as routing technical issues to outside vendor companies. By default it would also be forced into a reactive mode of operation, since its responsiveness to technical matters would be dependent on the responsiveness of the outsourced vendor company. There is also little chance of proactively matching strategic business requirements and innovative technologies as an R \& D division is non-existent. These relationships with the role and mode of operation of the IT department therefore make the sourcing option of the IT department a very influential antecedent to the problem of aligning business and IT.

\section{Research Design and Methodology}

Table 1 summarises the research design of this study. 
Table 1. Research Design

\begin{tabular}{|c|c|}
\hline Component & Description \\
\hline Problem & $\begin{array}{l}\text { The alignment of business and IT has proved to be a difficult state to attain and maintain. We know from } \\
\text { previous studies that the solution may lie in the prerequisites for or antecedents to the problem of } \\
\text { business and IT alignment, the most fundamental of which is the role of the IT department. }\end{array}$ \\
\hline Research question & $\begin{array}{l}\text { What other antecedents to the business and IT alignment problem exist, and how are they related to the } \\
\text { role of the IT department? }\end{array}$ \\
\hline Context & Managing an IT department within an organization \\
\hline Propositions* & $\begin{array}{l}\text { 1: The mode of operation of the IT department is an antecedent that is related to the role of the IT } \\
\text { department. } \\
\text { 2: The sourcing option of IT is an antecedent that is related to the role of the IT department and the mode } \\
\text { of operation of the IT department. } \\
\text { 3: These antecedents can be used to identify states of stability and anomaly of the IT department with } \\
\text { regard to alignment. }\end{array}$ \\
\hline $\begin{array}{l}\text { Phenomenon } \\
\text { Investigated/Unit of } \\
\text { analysis }\end{array}$ & $\begin{array}{l}\text { Mode of operation of the IT department } \\
\text { Sourcing option of the IT department }\end{array}$ \\
\hline Unit of observation & Employees within the case organization \\
\hline Method & Electronic survey \\
\hline $\begin{array}{l}\text { Logic linking the data } \\
\text { to the propositions }\end{array}$ & $\begin{array}{l}\text { The appropriate value ratings of the antecedents of role of the IT department, mode of operation of the IT } \\
\text { department and sourcing option of the IT department can be measured by surveying the employees of } \\
\text { the organization. The value ratings of these antecedents can then provide the boundary conditions for an } \\
\text { IT department strategy that is aligned with business but that also takes into consideration the current and } \\
\text { desired states of the IT department. }\end{array}$ \\
\hline $\begin{array}{l}\text { Criteria for } \\
\text { interpreting the } \\
\text { findings }\end{array}$ & $\begin{array}{l}\text { Values assigned by respondents to the role of the IT department and the mode of operation of the IT } \\
\text { department on the role-mode plane (Figure 1). }\end{array}$ \\
\hline
\end{tabular}

\subsection{Sampling}

The target population for this study was the employees of a large organization in the financial sector in South Africa that has elected to be anonymous. The unit of observation was the individual employee. This case organization was particularly appropriate because of its size, many hierarchical levels of management, functions within the organization and its high dependence on technology.

A list of all the employees of the organization with their email addresses was generated from the company's human resource database by a database administrator. This list served as the sampling frame. After obtaining the permission and ethical clearance of senior management, an email with a link to a web-based survey application was sent to all employees of the organization. For a population of 1659 employees, with a confidence level of $95 \%$ and a confidence interval of $5 \%$, the targeted sample size was calculated to be 312 responses. The final sample included 324 voluntary responses, making the response rate $20 \%$. Due to the validation on the survey application all 324 responses were complete and therefore useable for analysis.

\subsection{Data Collection}

The survey questionnaire was pre-tested to determine whether the questions were reasonably understandable and whether they would be interpreted correctly. Three employees were asked to complete the questionnaire while the researcher was present and observed their understanding of the questions. Each respondent was asked to specifically point out to the researcher whether anything was unclear. Adjustments were made and the survey was sent out to all the employees of the organization. 


\subsection{Demographic variables}

The demographic variables that were measured were department and function. Department broadly classified whether the respondent belonged to the IT department or a client department of IT. The function demographic classified respondents into managers, technical staff, administrators or combinations thereof.

\section{Findings}

The findings for the case organization's IT department mode of operation and sourcing options follow. The mode of operation was operationalised by measuring perceptions of responsiveness of the IT department to core services such as maintaining systems, enhancing systems and procuring systems. The sourcing options were operationalised by measuring opinions of sourcing core skills of the IT department, such as infrastructure specialists, software developers and desktop support staff.

\subsection{Current and ideal modes of operation}

The results presented in Tables 3 to 5 contain Kappa statistics that show a degree of agreement between two variables. Table 2 is provided to assist interpretation of the Kappa statistic ranges for the reader. Tables 3 to 5 report the agreement ratings for key constructs of this research.

Table 2. Interpretation of Kappa values for agreement between perspectives (Viera \& Garrett, 2005:360)

\begin{tabular}{|c|c|}
\hline Kappa & Agreement \\
\hline$<0$ & Less than chance agreement \\
\hline $0.01-0.20$ & Slight agreement \\
\hline $0.21-0.40$ & Fair agreement \\
\hline $0.41-0.60$ & Moderate agreement \\
\hline $0.61-0.80$ & Substantial agreement \\
\hline $0.81-0.99$ & Almost perfect agreement \\
\hline
\end{tabular}

\subsubsection{Maintaining systems}

Evaluating how maintaining of systems is perceived, the Kappa statistic in Table 3 of approximately 0.13 indicates only a slight agreement between current and ideal perspectives of the mode of operation of the IT department with respect to maintenance of IT systems. Only $26.85 \%$ consistently agree, both currently and ideally, that the IT department operates proactively with respect to maintaining systems. Almost $80 \%$ (78.70) believe that IT should, ideally, operate proactively. The main differences come from the almost $52 \%(32.72 \%+19.14 \%)$ of respondents who believe that IT is currently reactive (or are undecided) but ideally prefer it to be proactive.

Table 3. Mode of Operation of the IT department: Comparing current and ideal views of how "Maintaining systems" is perceived

\begin{tabular}{|c|c|c|c|c|c|}
\hline \multicolumn{2}{|c|}{ Kappa Statistic: 0.1299} & \multicolumn{3}{|c|}{ Ideal } & \multirow[b]{2}{*}{ Totals (current) } \\
\hline & $\begin{array}{c}\text { Number } \\
(\%)\end{array}$ & Reactive & Undecided & Proactive & \\
\hline \multirow{4}{*}{ 䓂 } & Reactive & $\begin{array}{c}22 \\
(6.79)\end{array}$ & $\begin{array}{c}19 \\
(5.86)\end{array}$ & $\begin{array}{c}106 \\
(32.72)\end{array}$ & $\begin{array}{c}147 \\
(45.37)\end{array}$ \\
\hline & Undecided & $\begin{array}{c}6 \\
(1.85) \\
\end{array}$ & $\begin{array}{c}17 \\
(5.25) \\
\end{array}$ & $\begin{array}{c}62 \\
(19.14) \\
\end{array}$ & $\begin{array}{c}85 \\
(26.23) \\
\end{array}$ \\
\hline & Proactive & $\begin{array}{c}3 \\
(0.93)\end{array}$ & $\begin{array}{c}2 \\
(0.62)\end{array}$ & $\begin{array}{c}87 \\
(26.85)\end{array}$ & $\begin{array}{c}92 \\
(28.40)\end{array}$ \\
\hline & Totals (ideal) & $\begin{array}{c}31 \\
(9.57) \\
\end{array}$ & $\begin{array}{c}38 \\
(11.73) \\
\end{array}$ & $\begin{array}{c}255 \\
(78.70) \\
\end{array}$ & $\begin{array}{c}324 \\
(100.00) \\
\end{array}$ \\
\hline
\end{tabular}




\subsubsection{Enhancing systems}

The Kappa statistic of 0.09 for how enhancing of systems is perceived (Table 4) is similar to that on how maintaining of systems is perceived, showing only slight agreement between current and ideal perspectives of the mode of operation of the IT department with respect to enhancement of systems.

Table 4. Mode of operation of the IT department: Comparing current and ideal views of how "Enhancing systems" is perceived

\begin{tabular}{|c|c|c|c|c|c|}
\hline \multicolumn{2}{|c|}{ Kappa Statistic: 0.0915} & \multicolumn{3}{|c|}{ Ideal } & \multirow[b]{2}{*}{ Totals (current) } \\
\hline & $\begin{array}{c}\text { Number } \\
(\%)\end{array}$ & Reactive & Undecided & Proactive & \\
\hline \multirow{4}{*}{ 窇 } & Reactive & $\begin{array}{c}17 \\
(5.25) \\
\end{array}$ & $\begin{array}{c}12 \\
(3.70) \\
\end{array}$ & $\begin{array}{c}93 \\
(28.70) \\
\end{array}$ & $\begin{array}{c}122 \\
(37.65) \\
\end{array}$ \\
\hline & Undecided & $\begin{array}{c}7 \\
(2.16) \\
\end{array}$ & $\begin{array}{c}21 \\
(6.48) \\
\end{array}$ & $\begin{array}{c}72 \\
(22.22) \\
\end{array}$ & $\begin{array}{c}100 \\
(30.86) \\
\end{array}$ \\
\hline & Proactive & $\begin{array}{c}10 \\
(3.09)\end{array}$ & $\begin{array}{c}6 \\
(1.85)\end{array}$ & $\begin{array}{c}86 \\
(26.54)\end{array}$ & $\begin{array}{c}102 \\
(31.48)\end{array}$ \\
\hline & Totals (ideal) & $\begin{array}{c}34 \\
(10.49) \\
\end{array}$ & $\begin{array}{c}39 \\
(12.04) \\
\end{array}$ & $\begin{array}{c}251 \\
(77.47) \\
\end{array}$ & $\begin{array}{c}324 \\
(100.00) \\
\end{array}$ \\
\hline
\end{tabular}

As with maintenance of systems, only one quarter (26.54\%) consistently agree, both currently and ideally, that the IT department operates proactively with respect to enhancement of systems. Almost $80 \%$ (77.47\%) believe that IT should, ideally, operate proactively. The main differences come from the almost $50 \%(28.70 \%+22.22 \%)$ of respondents who are undecided or believe that IT is currently reactive, but ideally prefer it to be proactive.

\subsubsection{Procuring systems}

The Kappa statistic of 0.14 in Table 5 also shows only a slight agreement between current and ideal perspectives of the mode of operation of the IT department with respect to procurement of systems.

Table 5. Mode of operation of the IT department: Comparing current and ideal views of how "Procurement of systems" is perceived

\begin{tabular}{|c|c|c|c|c|c|}
\hline \multicolumn{2}{|c|}{ Kappa Statistic: 0.1432} & \multicolumn{3}{|c|}{ Ideal } & \multirow[b]{2}{*}{ Totals (current) } \\
\hline & $\begin{array}{c}\text { Number } \\
(\%)\end{array}$ & Reactive & Undecided & Proactive & \\
\hline \multirow{3}{*}{ 蒙 } & Reactive & $\begin{array}{c}14 \\
(4.32)\end{array}$ & $\begin{array}{c}19 \\
(5.86)\end{array}$ & $\begin{array}{c}69 \\
(21.30)\end{array}$ & $\begin{array}{c}102 \\
(31.48)\end{array}$ \\
\hline & Undecided & $\begin{array}{c}12 \\
(3.70)\end{array}$ & $\begin{array}{c}35 \\
(10.80)\end{array}$ & $\begin{array}{c}63 \\
(19.44)\end{array}$ & $\begin{array}{c}110 \\
(33.95)\end{array}$ \\
\hline & Proactive & $\begin{array}{c}13 \\
(4.01)\end{array}$ & $\begin{array}{c}7 \\
(2.16)\end{array}$ & $\begin{array}{c}92 \\
(28.40)\end{array}$ & $\begin{array}{c}112 \\
(34.57)\end{array}$ \\
\hline & Totals (ideal) & $\begin{array}{c}39 \\
(12.04)\end{array}$ & $\begin{array}{c}61 \\
(18.83)\end{array}$ & $\begin{array}{c}224 \\
(69.14)\end{array}$ & $\begin{array}{c}324 \\
(100.00)\end{array}$ \\
\hline
\end{tabular}

As with maintenance and enhancing of systems, just over one quarter (28.40\%), both currently and ideally agree that the IT department operates proactively with respect to procurement of systems. Almost $70 \%$ (69.14\%) believe that IT should ideally be proactive. The significant differences are attributed to the almost $40 \%(21.30 \%+19.44 \%)$ who are undecided or believe that IT is currently reactive, but believe that it should ideally be proactive. The trend for procurement of systems is very similar to that for maintenance and enhancement of systems (Tables 3 and 4), except that more respondents are currently undecided than believe IT is currently reactive. 


\subsection{Mode of operation across function and department}

Table 6 shows the results of the Repeated Measures ANOVA where the dependent variable is the current mode of operation of the IT department and the demographic factors are function and department.

Table 6. Repeated Measures ANOVA - Current and ideal modes of operation of the IT department (DV) - Function and Department (Factors)

\begin{tabular}{|l|c|c|c|}
\hline Source for current rating & DF & F Value & $\operatorname{Pr}>$ F \\
\hline Current Mode of Operation & 2 & 5.93 & $0.0028^{\star \star}$ \\
\hline Current Mode of Operation * Function & 10 & 0.55 & 0.8555 \\
\hline Current Mode of Operation * Department & 2 & 0.33 & 0.7186 \\
\hline Source for ideal rating & DF & F Value & $\operatorname{Pr}>$ F \\
\hline Ideal Mode of Operation & 2 & 5.81 & $0.0032^{\star \star}$ \\
\hline Ideal Mode of Operation * Function & 10 & 1.65 & 0.0879 \\
\hline Ideal Mode of Operation * Department & 2 & 0.63 & 0.5332 \\
\hline
\end{tabular}

The demographic factors of function and department had no influence on measurements of the current mode of operation ( $p$-values of 0.8555 and 0.7186 , respectively). Similarly, the demographic factors of function and department had no influence on the ideal mode of operation of IT ( $p$-values of 0.0879 and 0.5332 , respectively).

\subsection{Sourcing of core services: outsource or in-house}

Table 7 indicates that over the entire sample there is a very clear preference for keeping all IT services in-house.

Table 7. Resources of IT: Preference of sourcing options stating where IT services should be sourced

\begin{tabular}{|l|c|c|}
\hline Variable & Mean & Median \\
\hline Infrastructure Specialists & 4.05 & 5.0 \\
\hline Software Developers & 3.74 & 4.0 \\
\hline IT Support & 4.01 & 5.0 \\
\hline Technical Focus & 4.16 & 5.0 \\
\hline
\end{tabular}

Note: 1=Outsource, $5=$ In-house

\subsection{Sourcing of core services across function and department}

Table 8 shows the results of the Repeated Measures ANOVA where the dependent variable is the resources of IT and the demographic factors are function and department.

Table 8. Repeated Measures ANOVA - Resources of IT (DV) - Function and Department (Factors)

\begin{tabular}{|l|c|c|c|}
\hline Source & DF & F Value & Pr > F \\
\hline Resources of IT & 2 & 5.78 & $0.0032^{\star \star}$ \\
\hline Resources of IT * Function & 10 & 1.33 & 0.2099 \\
\hline Resources of IT * Department & 2 & 8.40 & $0.0003^{\star \star}$ \\
\hline
\end{tabular}

The function demographic had no influence on the resources of IT ( $p$-value of 0.2099 ) but the department demographic did (p-value of 0.0003$)$.

Table 9 shows the results of an ANOVA that further explores the interaction of the department factor on the resources of IT by determining which of the resources of IT, namely, infrastructure specialists, software developers and desktop support are affected by department. It compares the variances in each of the resource pairs. 
Table 9. ANOVA of resource pairs

\begin{tabular}{|c|c|c|c|}
\hline Source - infrastructure vs developers & DF & F Value & $\operatorname{Pr}>$ F \\
\hline Mean & 1 & 9.83 & $0.0019^{\star \star}$ \\
\hline Function & 5 & 0.83 & 0.5305 \\
\hline Department & 1 & 0.49 & 0.4839 \\
\hline Mean & DF & F Value & $\operatorname{Pr}>$ F \\
\hline Function & 1 & 0.03 & 0.8573 \\
\hline Department & 5 & 1.79 & 0.1135 \\
\hline Source - infrastructure vs desktop support & 1 & 11.75 & $0.0007^{\star \star}$ \\
\hline Mean & DF & F Value & $\operatorname{Pr}>$ F \\
\hline Function & 1 & 10.02 & $0.0017^{\star *}$ \\
\hline Department & 5 & 1.19 & 0.3118 \\
\hline & 1 & 12.43 & $0.0005^{\star \star}$ \\
\hline
\end{tabular}

The resource pair of infrastructure specialists and software developers are not significantly affected by demographic factor, function or department ( $p$-values of 0.5305 and 0.4839 , respectively). The resource pair of software developers and IT support are affected by the department demographic only ( $p$-value of 0.0007 ). Similarly, the resource pair consisting of infrastructure specialists and IT support are also affected by the department factor ( $p$-value of 0.0005). The magnitude and direction of this interaction of the department factor is presented in Table 10 and is observable through the means and mean differences for the resources of IT with respect to department.

Table 10. Means of Resources of IT per Department

\begin{tabular}{|l|c|c|}
\hline Resources & Client Departments & IT Department \\
\hline Infrastructure Specialists & 4.04 & 4.12 \\
\hline Software Developers & 3.72 & 3.86 \\
\hline IT Support & 4.08 & 3.61 \\
\hline Mean differences & & \\
\hline Infrastructure - Developers & $0.32^{\mathrm{a}}$ & $0.26^{\mathrm{a}}$ \\
\hline Infrastructure - Support & $-0.04^{\mathrm{a}}$ & $0.51^{\mathrm{b}}$ \\
\hline Developers - Support & $-0.36^{\mathrm{a}}$ & $0.25^{\mathrm{b}}$ \\
\hline
\end{tabular}

Note: Mean differences with different superscripts represent significant differences (within columns) in trend between Client and IT departments.

Comparing the preference for keeping infrastructure specialists and software developers in-house, it can be noted that although the preference is higher for infrastructure specialists than software developers, the difference in means is in the same proportion and direction for the client departments and the IT department. However, when comparing infrastructure specialists and IT support, and software developers and IT support, differences in means are in opposite directions. That is, client departments have a higher preference for keeping IT support in-house, whereas the IT department has a higher preference for keeping infrastructure specialists and software developers in-house.

\section{Discussion}

This study therefore started out with the purpose of establishing the mode of operation and sourcing option of the IT department as antecedents to alignment, showing how they relate to the role of the IT department and how they could be used to approach stability that would facilitate alignment within the context of a particular organization. The academic importance of this study lies in changing the focus of the alignment problem to the prerequisites for or antecedents of alignment and their relationships. The practical importance stems from the use of these theories in solving the alignment problem in the contexts in which they occur.

\subsection{Discussion of the findings}

In the context of the organization being observed, the results show that the mode of operation of the IT department is currently a reactive mode of operation and that employees would ideally prefer a proactive mode of operation. 
Furthermore, these findings are not affected by either department or function. That is, these findings are unanimous across both IT and client staff (department demographic) as well as across managerial, technical and administrative staff (function demographic). The finding that IT should ideally operate proactively appears contradictory to the philosophy within the organization of only supplying a product/service if there is a clear business demand for it. The ideally proactive mode of operation is also contradictory to the finding that the role of the IT department within this organization was unanimously measured as a utility role. It therefore appears that the organization is an anomalous state. On the one hand the IT department is given the mandate of a utility role which should be focused on low-cost, on-demand, generic IT services with no R \& D capability to research new innovative technologies. On the other hand it is expected to operate in a proactive mode.

The findings with respect to the resource preferences for IT show that, irrespective of department or function, respondent employees generally prefer IT services to remain in-house and that IT should have a technical focus. This is contradictory to the way that the IT department is currently operating, since outsourcing is the predominant sourcing option used within the organization and there is also an administrative focus. While function had no influence on views on IT sourcing, for departments some differences did emerge about which IT resources are more preferred than others. It appears that although both client and IT staff would prefer all IT services to be in-house, the client departments have a higher preference for keeping IT support in-house, while the IT department itself would prefer to have infrastructure and software development in-house. This is consistent with the clients' attitude that they are not so much concerned with how IT gets the job done but that IT should be available to provide support when there is an interruption to business due to an IT problem. There appears to be a belief that having infrastructure and software development in-house will support the primary need of efficient IT support.

\subsection{Practical managerial implications based on a proposed framework}

The managerial implications of this study can be explained at a generic level and at a level specific to the context of the organization in this study. The framework, however, provides some guidelines for generalization after being observed in the case study. Figure 1 proposes a framework to demonstrate the generic use of the antecedents the role of the IT department and mode of operation of the IT department in practice.

\begin{tabular}{|c|c|c|c|}
\hline \multirow{2}{*}{ 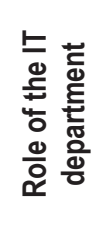 } & 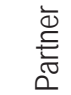 & $\begin{array}{l}\text { Constrained } \\
\text { Innovator }\end{array}$ & $\begin{array}{l}\text { Realised } \\
\text { Innovator }\end{array}$ \\
\hline & 晨 & $\begin{array}{l}\text { Satisfied } \\
\text { Utilitarian }\end{array}$ & $\begin{array}{c}\text { Constrained } \\
\text { Utilitarian }\end{array}$ \\
\hline
\end{tabular}

Figure 1. Framework for categorizing IT departments on Role of the IT department versus Mode of Operation of the IT Department

Figure 1 plots the role of the IT department against the mode of operation of the IT department on a two-dimensional plane, showing the different combinations of these antecedents. The bottom half represents IT when mandated a utility role; hence an IT department that falls in the lower hemisphere is termed utilitarian. The top half represents IT when mandated a business partner role. Since the business partner role requires an IT department to continuously match innovative technologies with the needs of business, an IT department that falls in the upper hemisphere is termed an innovator. The mode of operation variable splits the plane into a reactive behaviour on the left half and a proactive behaviour on the right half. This splits the plane into four quadrants with two stable states, the satisfied utilitarian and realised innovator, and two anomalous states, the constrained innovator and the constrained utilitarian. Each of the categories is discussed for practical application.

Satisfied Utilitarian:

An IT department in the bottom left quadrant is characterised by being mandated a utility role by the organization and by operating in a reactive manner. Since the utility role entails providing basic IT services on demand and at low cost, a reactive mode of operation would be expected. An IT department that is behaving as expected, in an organization that is satisfied with this mode of operation could be termed Satisfied Utilitarian.

Realised Innovator: 
An IT department in the top right quadrant is characterised by being mandated a strategic partner role by the organization and by operating in a proactive manner. The strategic partner role requires that the IT department be included in the strategic process and be mandated to pursue innovative technology to support the strategies. If the IT department manages to gear itself to constantly match innovative technology with the strategic needs of the organization, then it has realised its potential of being an innovator; hence the label Realised Innovator. Innovative technology then "leads" the strategy development.

Constrained Utilitarian:

An IT department in the bottom right quadrant is one that is being mandated a utility role but attempts, or is maybe expected, to operate proactively. The utility role means supplying basic IT services on demand at low cost. Such an IT department would therefore be administratively focused and may have outsourced core technical services. Operating proactively would therefore be difficult to achieve, since response to technical issues would be totally dependent on the schedule of the technical vendor. The IT managers are therefore operating under considerable constraints if they hope to perform proactively or meet client departments' expectations of a proactive response. The Constrained Utilitarian is therefore an anomalous state contributing to misalignment.

Constrained Innovator:

An IT department in the top left quadrant is one that has been mandated a strategic partner role but is operating in a reactive manner. That is, the IT department is expected to seek out innovative technologies and match them to business strategy, but fails to do so in a proactive manner. The reason for the reactive mode of operation may often be related to the sourcing option of the IT department's core services. If the IT department has elected to outsource its core services then the reactive mode of operation is due to a sourcing constraint. If its core services are in-house, then the reactive mode of operation is by choice (self-constrained). The Constrained Innovator is therefore an anomalous state contributing to misalignment.

The anomalous states of Constrained Utilitarian and Constrained Innovator are therefore both moderated mainly by the pursued sourcing options, which may be inappropriate for the combination of role and mode of operation of the IT department.

The managerial application in the specific context of the organization examined in this study would start by first plotting its IT department on the role-mode matrix and analysing the way in which it is sourcing its core services. From the findings, the case organization is clearly mandated a utility role. However, its mode of operation is currently perceived as reactive, but its expected (ideal) mode of operation is proactive. This would make it currently a Satisfied Utilitarian, but expected to be (ideally) a Constrained Utilitarian. The fact that its sourcing option is mainly outsourcing would make it difficult for such an IT department to satisfy the expectations of a proactive mode of operation. However, now being able to see their situation clearly, IT managers and executive managers can now devise ways to reach one of the two stable states. They could either campaign to curb the proactive expectation and stay in a Satisfied Utilitarian state, or change their sourcing model to keep core IT services in-house, facilitate R\&D and innovation, and basically move towards a Realised Innovator state. Based on the finding that ideally the desired sourcing option was measured to be in-house, it would be advisable for this particular organization to strive for the Realised Innovator state to satisfy the proactive expectation. The management would therefore need to renegotiate the mandate of the IT department to a business partner and increase its complement of technical staff, such as infrastructure specialists and software developers, and possibly introduce an R\&D division.

The proposed matrix has value for organizations during the analysis phase of strategic planning. It could enhance insight and eventually assist decision makers in addressing alignment problems. The framework is a tool that could enhance consultant contributions to organizations.

\subsection{Study limitations}

One limitation of this study was that for the function demographic split there was no way of determining the populations of each functional group, due to occasional dual-function categorizations. This was especially true for administrative functions. It was therefore not possible to compute minimum samples of each functional group. However, if there were some error due to the function sample sizes not being representative of the function populations, some deeper detail in the understanding of the dynamics could have been missed. Secondly, as the research was done in a case organization, care should be taken not to apply the matrix blindly without measuring antecedent values for each case. 


\subsection{Recommendations for future research}

Future research should further explore the relationships between these alignment antecedent variables, as they clarify alignment strategies that follow. There are several permutations of relationships between the role, mode of operation and sourcing of the IT department that could be investigated. For instance, it could be said that the role of the IT department could explain the mode of operation of the IT department, suggesting that the role of the IT department could possibly play a mediating role in the relationship between mode of operation of the IT department and alignment strategy. Another relationship might be considering the sourcing option of the IT department as a slowly changing variable, or even a constant, as changing staff complement is usually not a quick change that could be made to an organization. This then leaves only two variables to consider. Yet another permutation, and perhaps a long-term view, is to deliberately ignore the current resource level within the organization, strategically decide what the desired role and mode of operation of the IT department should be and then work towards building a resource complement to meet that goal.

\section{Conclusion}

The role, mode of operation and sourcing option of the IT department have been found to be interrelated to one another in a ways that explain why an IT department operates the way it does. A lack of understanding of the existence of, and relationship between, these antecedent variables can easily lead to management having vastly different perspectives about how the IT department should be run within a particular organization. In some cases these perspectives may even be counterproductive. This contradiction of perspectives is especially true in large organizations, or organizations with many levels of management hierarchy. Without a focused view of these fundamental characteristics of the IT department, managers tend to adopt the generic results of IT research companies, which may not be applicable to the context of their particular organization. In such states of confused management it is very difficult to even attempt to align the efforts of the IT department with the goals of the organization. The role, mode of operation and sourcing option of the IT department are therefore considered to be prerequisites for or antecedents to any endeavour to align business and IT. It is hoped that the naming, measuring and modelling of the antecedents in this research will contribute positively to the enduring quest to align business and IT.

\section{References}

Augier, M., Shariq, S.Z. \& Vendelø, M.T. 2001. Understanding context: its emergence, transformation and role in tacit knowledge sharing. Journal of Knowledge Management, 5(2):125-137.

Avison, D., Jones, J., Powell, P. \& Wilson, D. 2004. Using and validating the strategic alignment model. The Journal of Strategic Information Systems, 13(3):223-246.

Baets, W.R.J. 1996. Some empirical evidence on IS Strategy Alignment in banking. Information \& Management, 30(4):155-177.

Broadbent, M., Butler, C. \& Hansell, A. 1994. Business and technology agenda for information systems executives. International Journal of Information Management, 14(6):411-426.

Brown, C.V. 2007. Seamless IT alignment. In: Chowdhury, S. (Ed.), Next generation business handbook: New strategies from tomorrow's business leaders. Hoboken, NJ: Wiley.

Cao, Q. \& Hoffman, J.J. 2011. Alignment of virtual enterprise, information technology, and performance: an empirical study. International Journal of Production Research, 49(4):1127-1149.

Castellanos, C. \& Correal, D. 2013. A framework for alignment of data and processes architectures applied in a government institution. Journal on Data Semantics, 2(2-3):61-74.

Chan, Y.C. \& Reich, B.H. 2007. IT alignment: what have we learned? Journal of Information Technology (Palgrave Macmillan), 22(4):297-315.

Chen, L. 2010. Business-IT alignment maturity of companies in China. Information \& Management, 47(1):9-16.

Cragg, P., King, M. \& Hussin, H. 2002. IT alignment and firm performance in small manufacturing firms. Journal of Strategic Information Systems, 11(2):109-132.

Dong, X., Liu, Q. \& Yin, D. 2008. Business performance, business strategy, and information system strategic alignment: An empirical study on Chinese firms. Tsinghua Science \& Technology, 13(3):348-354.

Garg, J.A.K. \& Pellissier, R.J.O. 2005. Information systems environmental alignment and business performance : a case study. South African Journal of Business Management, 36(4):33-53.

Grant, G.G. 2003. Strategic alignment and enterprise systems implementation: the case of Metalco. Journal of Information Technology, 18(3):159-175.

Huang, C.D. \& Hu, Q. 2007. Achieving IT-business strategic alignment via enterprise-wide implementation of balanced scorecards. Information Systems Management, 24(2):173-184.

Jonassen, D. 2000. Toward a design theory of problem solving. Educational Technology Research and Development, 48(4):63-85. 
Kearns, G.S. \& Lederer, A.L. 2003. A resource-based view of strategic IT alignment: how knowledge sharing creates competitive advantage. Decision Sciences, 34(1):1-29.

Kokinov, B. \& Yoveva, M. 1996. Context effects on problem solving. Proceedings of the 18th Annual Conference of the Cognitive Science Society. Hillsdale; NJ: Erlbaum, 1-5.

Lepmets, M., McBride, T. \& Ras, E. 2012. Goal alignment in process improvement. Journal of Systems and Software, 85(6):1440-1452.

Norton, D.P. 2002. The alignment enigma. ClO Insight, (15):12.

Raymond, L. \& Bergeron, F. 2008. Enabling the business strategy of SMEs through e-business capabilities. Industrial Management \& Data Systems, 108(5):577-595.

Reich, B.H. \& Benbasat, I. 2000. Factors that influence the social dimension of alignment between business and information technology objectives. MIS Quarterly, 24(1):81-113.

Sanders, N.R. 2005. IT alignment in supply chain relationships: A study of supplier benefits. Journal of Supply Chain Management, 41(2):4-13.

Silva, L., Figueroa B., E. \& González-Reinhart, J. 2007. Interpreting IS alignment: A multiple case study in professional organizations. Information and Organization, 17(4):232-265.

Singh, S.N. \& Woo, C. 2009. Investigating business-IT alignment through multi-disciplinary goal concepts. Requirements Engineering, 14(3):177-207.

Smaczny, T. 2001. Is an alignment between business and information technology the appropriate paradigm to manage IT in today's organizations? Management Decision, 39(10):797.

Tallon, P.P. 2011. Value chain linkages and the spillover effects of strategic information technology alignment: A process-level view. Journal of Management Information Systems, 28(3):9-44.

Tallon, P.P. 2007. A process-oriented perspective on the alignment of information technology and business strategy. Journal of Management Information Systems, 24(3):227-268.

Tan, F.B. 1995. The responsiveness of information technology to business strategy formulation: an empirical study. Journal of Information Technology, 10(3):171-178.

Tarafdar, M. \& Qrunfleh, S. 2010. Examining tactical information technology-business alignmment. Journal of Computer Information Systems, 50(4):107-116.

Ullah, A. \& Lai, R. 2011. Modelling business goals for business/IT alignment using requirements engineering. Journal of Computer Information Systems, 51(3):21-28.

Valorinta, M. 2011. IT alignment and the boundaries of the IT function. Journal of Information Technology, 26(1):46-59.

van der Zee, J.T.M. \& de Jong, B. 1999. Alignment is not enough: integrating business and Information Technology management with the balanced business scorecard. Journal of Management Information Systems, 16(2):137-156.

Viera, A.J. \& Garrett, J.M. 2005. Understanding interobserver agreement: the kappa statistic. Family Medicine, 37(5):360-363.

Wakabayashi, K. 2008. Relationship between business definition and corporate growth: The effect of functional alignment. Pacific Economic Review, 13(5):663-679. 